\title{
Fatal Hyperammonemic Brain Injury from Valproic Acid Exposure
}

\author{
Danny Bega $^{a} \quad$ Henrikas Vaitkevicius $^{a}$ Torrey A. Boland ${ }^{a}$ \\ Michael Murray ${ }^{b}$ Sherry H.-Y. Chou ${ }^{a}$ \\ ${ }^{a}$ Department of Neurology, Brigham and Women's Hospital, and \\ boston Children's Hospital, Department of Genetics, Harvard Medical School, \\ Boston, Mass., USA
}

\section{Key Words}

Hyperammonemia $\cdot$ Cerebral edema $\cdot$ Valproic acid

\begin{abstract}
Background: Hyperammonemia is known to cause neuronal injury, and can result from valproic acid exposure. Prompt reduction of elevated ammonia levels may prevent permanent neurological injury. We report a case of fatal hyperammonemic brain injury in a woman exposed to valproic acid.
\end{abstract}

Case: A 38-year-old woman with schizoaffective disorder and recent increase in valproic acid dosage presented with somnolence and confusion and rapidly progressed to obtundation. Brain MRI showed diffuse bilateral restricted diffusion in nearly the entire cerebral cortex. She had normal liver function tests but serum ammonia level was severely elevated at 288 $\mu \mathrm{mol} / \mathrm{l}$. Genetic testing showed no mutation in urea cycle enzymes. Despite successful elimination of ammonia with hemodialysis she developed fatal cerebral edema.

Conclusion: Cerebral edema secondary to hyperammonemia is potentially reversible if recognized early. Ammonia excretion can be facilitated by initiation of hemodialysis and administration of scavenging agents (sodium phenylacetate and sodium benzoate). Severe hyperammonemia can result from valproic acid exposure even in the absence of hepatotoxicity or inborn errors of metabolism. It is important to check serum ammonia in any patient with encephalopathy who has had recent valproic acid exposure.

\section{Introduction}

Hyperammonemia is a well-described cause of encephalopathy and cerebral edema. When ammonia levels rise in the brain there is a subsequent swelling of astrocytes which results from the conversion of ammonia to glutamine. The resulting 
inflammatory response and oxidative stress leads to cell loss through apoptosis [1]. Survival in cases of hyperammonemia requires management of intracerebral hypertension, supportive care and management of subclinical seizures (which appear in up to $40 \%$ of cases), and prompt reduction of ammonia levels either by reducing its production or facilitating its elimination. When hyperammonemia does not appear to be the direct result of liver failure, determining the cause can be challenging, but often points to a disorder in the urea cycle resulting in decreased ammonia elimination. Such disorders of ammonia metabolism may be inborn, although many medications, including valproic acid, can also disrupt the urea cycle. We report a case of fatal hyperammonemic encephalopathy and cerebral edema in a woman who was on valproate with normal liver function.

\section{Case Presentation}

We report the case of a 38-year-old Caucasian woman with schizoaffective disorder who presented to the hospital with one day of somnolence and confusion progressing to obtundation requiring intubation. She had been stable on perphenazine $4 \mathrm{mg}$ qAM and $6 \mathrm{mg}$ qPM and valproic acid until one week prior to presentation when her valproic acid was increased from $500 \mathrm{mg}$ once a day to $500 \mathrm{mg}$ twice a day in the setting of increased agitation and behavioral outbursts. She had also been in a lowimpact motor vehicle collision a month prior to presentation, and was taking cyclobenzaprine $10 \mathrm{mg}$ tid for neck pain. Her only additional home medication was sertraline $100 \mathrm{mg}$ qd. On presentation she was afebrile and tachycardic. She was rigid and clenching her jaw. She was not responsive to any stimuli. Her pupils were large and reactive and her eyes were intermittently deviated downward. She had slight withdrawal to painful stimuli in her upper extremities and posturing was noted in her lower extremities. She was hyperreflexic and had clonus in her ankles. She was given diphenhydramine and bromocriptine for initial concern for neuroleptic-malignant syndrome (serotonin syndrome was also considered). Laboratory work was notable for the following findings: urine toxicology screen positive for tricyclics and opiates, serum valproate level of $10.0 \mu \mathrm{g} / \mathrm{ml}$, normal basic metabolic panel, normal liver function panel (AST/SGOT $15 \mathrm{U} / \mathrm{l}$ and ALT/SGPT $15 \mathrm{U} / \mathrm{l}$ ), creatine kinase $295 \mathrm{U} / \mathrm{l}$, thyroid stimulating hormone level of $2.3 \mathrm{U} / \mathrm{ml}$, complete blood count with white blood cell count of 15,000 cells/ml. Her serum ammonia level was $288 \mu \mathrm{mol} / \mathrm{l}$. Additional laboratory results are included in table 1. Further work-up included a chest X-ray demonstrating a right lower lobe consolidation (thought to be secondary to aspiration), a lumbar puncture without any evidence of infection or inflammation (opening pressure was not recorded, and there was no evidence of clinical or radiographic herniation after the lumbar puncture), a head CT with diffuse loss of the cortical graywhite differentiation suggestive of cerebral edema, and an MRI of the brain with diffuse cortical restricted diffusion ( fig. 1). An initial EEG showed diffuse slowing, but no seizure activity.

We suspected that the patient was suffering from intracranial hypertension secondary to hyperammonemia-induced cerebral edema. In the setting of normal liver function studies an inborn disorder of urea cycle metabolism seemed likely, perhaps triggered by a recent increase in valproate dosing. To this effect, serum amino acid studies were notable for an elevated serum glutamine of $1,292 \mu \mathrm{mol} / \mathrm{l}$ (consistent with the finding of hyperammonemia), and decreased levels of arginine (21 $\mu \mathrm{mol} / \mathrm{l})$ and citrulline $(9 \mu \mathrm{mol} / \mathrm{l})$. No abnormal organic acids were detected. Table 1 provides a more complete listing of serum and urine amino acids levels. Serum orotic acid was elevated at 2.5 $\mathrm{mmol} / \mathrm{mol}-\mathrm{Cr}$. Genetic testing for ornithine transcarbamylase deficiency showed that no known OTC gene mutations were detected.

The patient was started on a cooling protocol as well as hyperosmolar therapy with mannitol and $23 \%$ sodium chloride solution for cerebral edema control. Hyperosmolar therapy administration and weaning follows a strict clinical protocol at our institution, where serum electrolytes and osmolality are monitored every $6 \mathrm{~h}$ or less, and serum sodium levels are kept within a very tight target range determined by the treating physicians. During weaning of hyperosmolar therapy, serum sodium is only allowed to decrease by $5 \mathrm{mEq} / \mathrm{l}$ every $24 \mathrm{~h}$, and patients are monitored clinically and radiographically for rebound cerebral edema. Ammonia excretion was facilitated by initiation of continuous venovenous hemofiltration (CVVH), as well as by administration of lactulose and 
scavenging agents (sodium phenylacetate and sodium benzoate) [2]. We attempted to decrease ammonia production by not allowing any protein intake and by administering arginine to help prevent protein catabolism (citrulline could not be obtained). After five days of CVVH her ammonia came down to $31 \mu \mathrm{mol} / \mathrm{l}$ and the dialysis was discontinued. She was found to be in nonconvulsive status epilepticus by EEG (with rhythmic activity starting in the occipital lobes; fig. 2 ) prompting the initiation of propofol and midazolam to induce burst suppression. Despite stopping depakote, her ammonia again began to rise up to $224 \mu \mathrm{mol} / \mathrm{l}$, and CVVH was re-initiated without any further success in reducing the serum ammonia level. On hospital day 11 she became bradycardic with dilated, nonreactive pupils despite maximum osmotic therapy. Repeat imaging of her brain showed complete effacement of the supracellar cisterns suggesting further increase in her intracranial pressure and uncal herniation with global anoxic injury ( $\underline{\text { fig. } 3}$ ). At that time her goals of care were transitioned to focus on comfort measures only and she was terminally extubated. At autopsy her brain showed evidence of severe edema with flattening of gyri and both uncal and cerebellar herniation. Histology showed frequent Alzheimer type II cells throughout the cortex. Her liver was slightly pale and mildly enlarged.

\section{Conclusion}

Ammonia is produced in the gastrointestinal tract as a by-product of protein digestion; it is then metabolized primarily in the liver as urea. In cases of liver failure or urea cycle enzyme deficiencies, the metabolic capacity of the liver is overwhelmed and elimination of ammonia becomes dependent on other organs such as the kidneys and brain. The brain does not have a urea cycle; instead, astrocytes metabolize ammonia to glutamine via glutamine synthetase, resulting in intracellular hyperosmolarity and subsequent swelling and cell loss. This process results in triggering of inflammatory cascades, activation of NMDA-receptor pathways, and apoptosis, which in turn causes elevation in lactate, loss of cerebral autoregulation, and cerebral edema [1,3]. Neuropathological studies in hyperammonemic syndromes reveal predominantly astrocytic swelling in the acute setting, and Alzheimer type II astrocytosis in the chronic setting [3]. Patients with hyperammonemia have elevated glutamine levels in serum, cerebrospinal fluid, and urine, and magnetic resonance spectroscopy can show high glutamine concentrations in the brains of patients with elevated ammonia regardless of the etiology. It is not clear why certain areas of the brain (i.e. the insular cortex, cingulate gyrus) seem particularly susceptible to the toxic effects of ammonia. It has been hypothesized that areas that are more metabolically active may be more affected by hypoperfusion and ischemia in the setting of elevated intracranial hypertension [4]. In the above case the MRI showed diffuse cortical involvement with some initial sparing of the primary motor and primary visual cortices (fig. 1); the significance of this pattern is unclear, but this has been demonstrated in previous case reports of hyperammonemic encephalopathy [5]. Previous case reports of hyperammonemic encephalopathy have also demonstrated the potential reversibility of cortical changes with aggressive treatment aimed at lowering the serum ammonia. In these cases, the extent of injury and reversibility also seemed to depend on the severity and duration of the hyperammonemia [3]. Reversible changes have not been described at levels of serum ammonia as high as that which our patient presented with.

Valproate-induced hyperammonemic encephalopathy has been reported even in the absence of hepatotoxicity. It has been proposed that valproate may increase transport of glutamine across mitochondrial membranes making it more available for production of ammonia. It may also indirectly result in inhibition of the activity of carbamoylphosphate synthase (CPS-1), a urea cycle enzyme, thereby decreasing ammonia 
excretion [6]. In the above case our patient's dose of valproate was recently doubled although her serum valproate level was not at a toxic level. This is consistent with previous case reports which have shown that the degree of hyperammonemia and encephalopathy is not necessarily related to the daily dose or serum valproate concentration [6]. It is worth noting that change in diet, stress of infection, exercise, and even hormones may influence ammonia levels. It remains unclear if the additional medications taken by our patient - sertraline, cyclobenzaprine, and perphenazine played any significant role in her presentation. Furthermore, none of these medications have been described as potential causes of hyperammonemia in the setting of normal hepatic function.

As described above, the presence of hyperammonemia in the setting of normal liver function studies raised a high level of suspicion for a possible inborn error of metabolism. In the urea cycle, ammonia is incorporated into an amino acid at each enzymatic step; accordingly, one ammonium ion is removed at each step until urea is formed. Hyperammonemia is most severe in these cases when the enzyme defect is an early step in the urea cycle, such as ornithine transcarbamylase (OTC) or carbamoylphosphate synthase (CPS). OTC deficiency is one of the most common inborn errors of metabolism of the urea cycle, and as an X-linked disorder can have late onset presentations in women due to random X-inactivation due to mosaicism in each hepatocyte. Our hypothesis that our patient had an inborn error of metabolism was supported by her low serum citrulline and arginine levels; a defect in either OTC or CPS, two enzymes responsible for steps in the urea cycle which lead to the formation of these amino acids, could explain this deficiency. An elevated orotic acid level would be seen in OTC deficiency, but not in CPS deficiency, since orotic acid is a by-product of the cycle which is made from carbamoyl phosphate when OTC is not available. Over 200 mutations have been identified in the ornithine carbamoyl transferase gene on chromosome Xp21, but genetic testing in this case did not show a recognized mutation. We cannot rule out the possibility that this patient may have had a novel mutation. In particular, a mutation in the promoter region of a gene, rather than the gene itself, may lead to similar deficiencies in key proteins of the urea cycle. 
Table 1. Laboratory data

\begin{tabular}{|c|c|c|c|c|c|c|c|c|}
\hline & $\begin{array}{l}\text { Value on } \\
\text { admission }\end{array}$ & Normal & $\begin{array}{l}\text { Plasma amino } \\
\text { acids }\end{array}$ & $\begin{array}{l}\text { Value on } \\
\text { admission }\end{array}$ & Normal & $\begin{array}{l}\text { Urine amino } \\
\text { acids }\end{array}$ & $\begin{array}{l}\text { Value on } \\
\text { admission }\end{array}$ & Normal \\
\hline $\mathrm{Na}$ & $143 \mathrm{mmol} / \mathrm{l}$ & $136-145$ & Alanine & 359 & $240-600$ & 1-Methylhistidine & 51 & $170-1,680$ \\
\hline $\mathrm{K}$ & $3.7 \mathrm{mmol} / \mathrm{l}$ & $3.5-5.0$ & Arginine & 21 & $40-160$ & Alanine & 343 & $240-670$ \\
\hline BUN & $8 \mathrm{mg} / \mathrm{dl}$ & $6-23$ & Aspartic acid & 9 & $0-20$ & Arginine & 65 & $10-90$ \\
\hline $\mathrm{Cr}$ & $0.74 \mathrm{mg} / \mathrm{dl}$ & $0.5-1.2$ & Citrulline & 9 & $10-60$ & Asparagine & 108 & $99-470$ \\
\hline ALT/GPT & $15 \mathrm{U} / \mathrm{l}$ & $10-50$ & Cystine & 26 & $7-70$ & Carnosine & 38 & $10-90$ \\
\hline AST/GOT & $15 \mathrm{U} / \mathrm{l}$ & $10-50$ & Glutamic acid & 56 & $10-120$ & Citrulline & 0 & $8-50$ \\
\hline $\mathrm{CK}$ & $295 \mathrm{U} / \mathrm{l}$ & $26-192$ & Glutamine & 1,292 & $410-700$ & Cystine & 16 & $43-210$ \\
\hline ALK PHOS & $55 \mathrm{U} / \mathrm{l}$ & $35-130$ & Glycine & 158 & $140-490$ & Glutamic acid & 5 & $39-330$ \\
\hline Tot Bili & $0.4 \mathrm{mg} / \mathrm{dl}$ & $0.0-1.0$ & Histidine & 88 & $50-130$ & Glutamine & 1,154 & $190-510$ \\
\hline Tot Prot & $7.0 \mathrm{~g} / \mathrm{dl}$ & $6.4-8.3$ & Homocystine & 0 & $0-0$ & Glycine & 2,657 & $730-4,160$ \\
\hline Albumin & $4.5 \mathrm{~g} / \mathrm{dl}$ & $3.5-5.2$ & Isoleucine & 24 & $30-130$ & Histidine & 392 & $460-1,430$ \\
\hline Glucose & $137 \mathrm{mg} / \mathrm{dl}$ & $54-118$ & Leucine & 88 & $60-230$ & Isoleucine & 5 & $16-180$ \\
\hline Ammonia & $288 \mu \mathrm{mol} / \mathrm{l}$ & $11-60$ & Lysine & 137 & $80-250$ & Leucine & 16 & $30-150$ \\
\hline WBC & $15.57 \mathrm{~K} / \mu \mathrm{l}$ & $4-10$ & Methionine & 17 & $17-53$ & Methionine & 8 & $38-210$ \\
\hline HGB & $14.5 \mathrm{~g} / \mathrm{dl}$ & $11.5-16.4$ & Omithine & 41 & $20-135$ & Ornithine & 3 & $20-80$ \\
\hline HCT & $42.10 \%$ & $36-48$ & Phenylalanine & 64 & $30-80$ & Phenylalanine & 19 & $51-250$ \\
\hline PLT & $350 \mathrm{~K} / \mu \mathrm{l}$ & $150-450$ & Proline & 342 & $110-500$ & Proline & 11 & 0.00 \\
\hline ESR & $5 \mathrm{~mm} / \mathrm{h}$ & $0-18$ & Serine & 73 & $60-200$ & Serine & 276 & $240-670$ \\
\hline PT (INR) & $1.1(\mathrm{~N} / \mathrm{A})$ & $0.9-1.1$ & Taurine & 38 & $25-80$ & Taurine & 46 & $380-1,850$ \\
\hline PTT & $27.2 \mathrm{~s}$ & $23.8-36.6$ & Threonine & 44 & $60-220$ & Threonine & 32 & $130-370$ \\
\hline VALP ACID & $10.0 \mu \mathrm{g} / \mathrm{ml}$ & $50-120$ & Tyrosine & 43 & $30-120$ & Tyrosine & 35 & $90-290$ \\
\hline ACET LEVEL & <assay, $\mu \mathrm{g} / \mathrm{ml}$ & $10-20$ & Valine & 143 & $140-350$ & Valine & 16 & $27-260$ \\
\hline HAV IgM & Negative & $\mathrm{n} / \mathrm{a}$ & & & & & & \\
\hline HBsAg & Negative & $\mathrm{n} / \mathrm{a}$ & & & & & & \\
\hline HBsAb & Negative & $\mathrm{n} / \mathrm{a}$ & & & & & & \\
\hline $\mathrm{HCV}$ & Negative & $\mathrm{n} / \mathrm{a}$ & & & & & & \\
\hline TrepAb & Nonreactive & $\mathrm{n} / \mathrm{a}$ & & & & & & \\
\hline Mycoplasma & Neg $\lg G+\operatorname{IgM}$ & $\mathrm{n} / \mathrm{a}$ & & & & & & \\
\hline Urine Organic & $\begin{array}{l}\text { No unusual } \\
\text { organic acids }\end{array}$ & $\mathrm{n} / \mathrm{a}$ & & & & & & \\
\hline Methylmalonic & $0.08 \mathrm{nmol} / \mathrm{l}$ & $0-0.4$ & & & & & & \\
\hline Serum Orotic & $\begin{array}{l}2.5 \mathrm{mmol} / \mathrm{mol}- \\
\mathrm{Cr}\end{array}$ & - $0.4-1.2$ & & & & & & \\
\hline
\end{tabular}




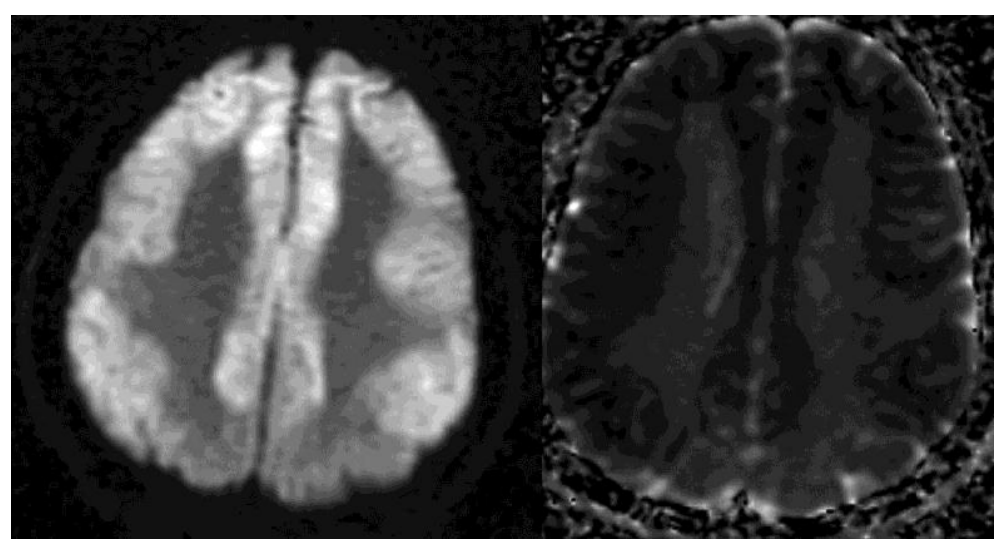

Fig. 1. MRI, hospital day 1. DWI on the left, ADC on the right.

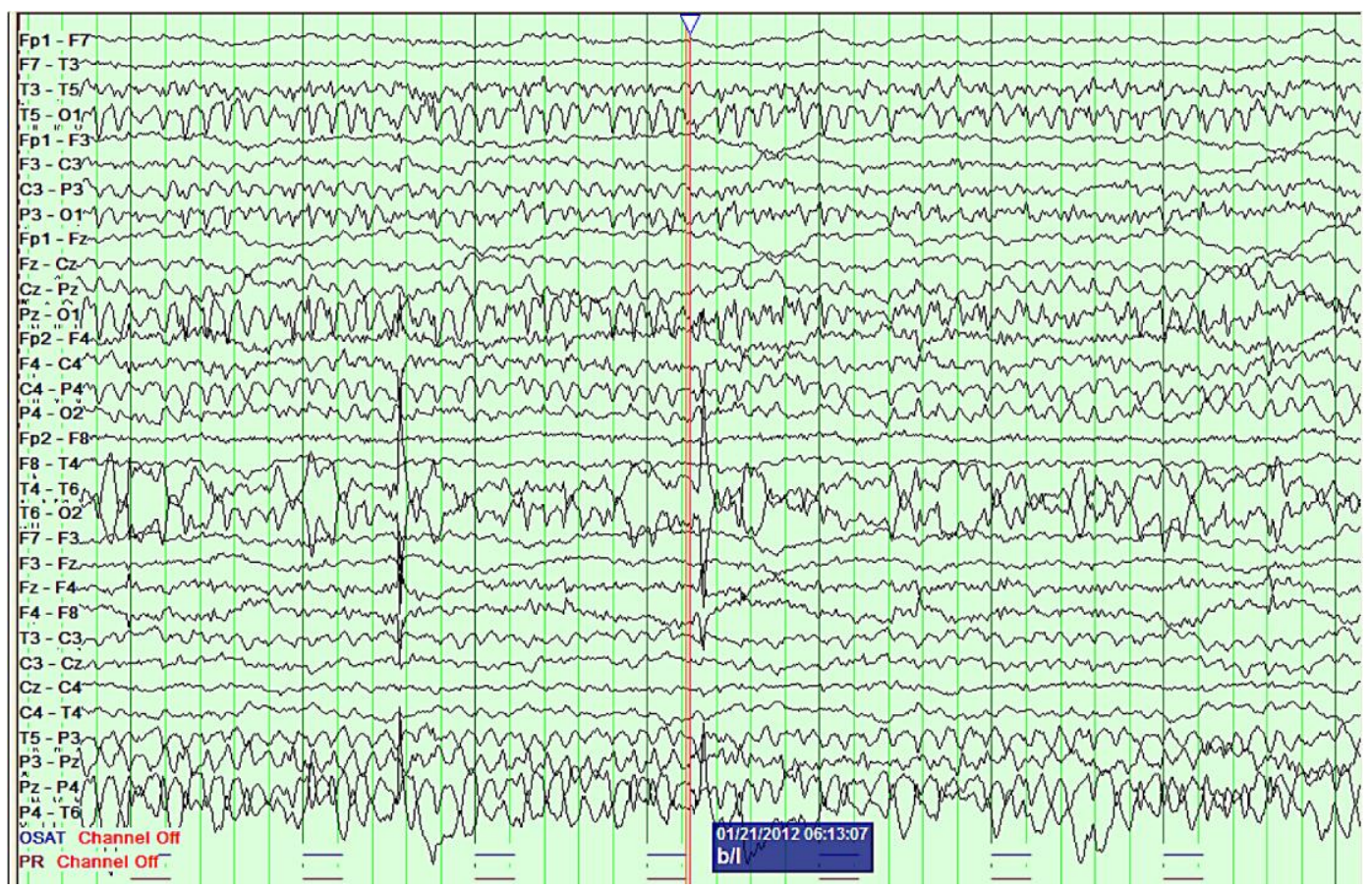

Fig. 2. EEG, hospital day 5. Rhythmic sharp theta discharges starting in the left occipital leads and evolving in amplitude, frequency and morphology, spreading to neighboring electrodes and to right occipital leads as well. 


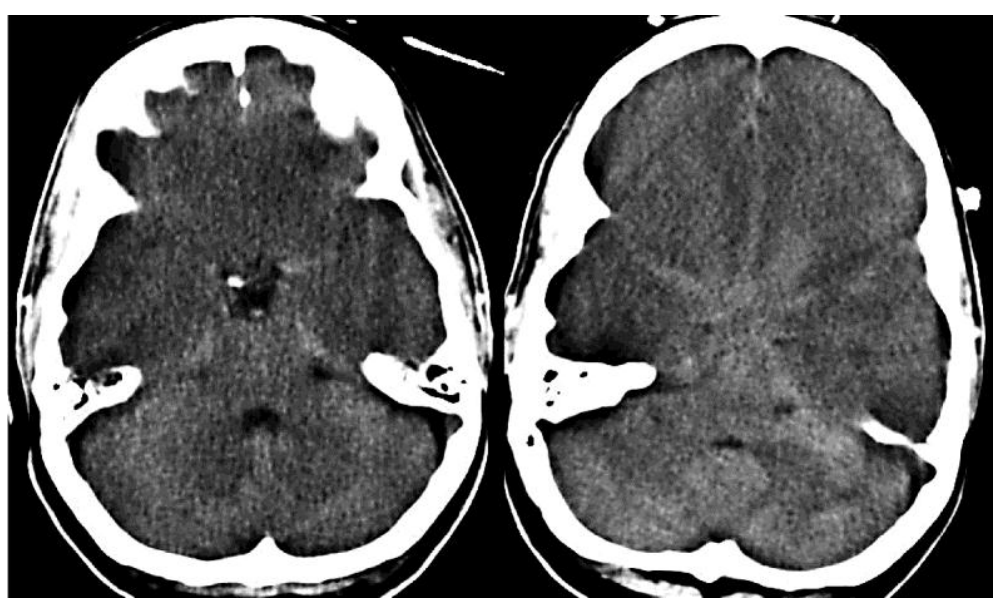

Fig. 3. CT, hospital day 1 on the left, hospital day 10 on the right.

\section{References}

1 Clay A, et al: Hyperammonemia in the ICU. Chest 2007;132:1368-1378.

2 Shih V: Alternative-pathway therapy for hyperammonemia. NEJM 2007;356:2321-2322.

3 Felipo V, et al: Neurobiology of ammonia. Progress in Neurobiol 2002;67:259-279.

$\checkmark 4$ U-King-Im J, et al: Acute hyperammonemic encephalopathy in adults: imaging findings. Am J Neuroradiol 2011;32:413-418.

5 Capizzano A, et al: Hyperammonemic encephalopathy: time course of MRI diffusion changes. Neurology 2012;78:600.

6 Gomcelli YB, et al: Different clinical manifestations of hyperammonemic encephalopathy. Epilepsy Behav 2007;10:583-587. 